\title{
Para aprender da pedra, frequentá-la
}

\author{
Joubert José Lancha*
}

Resumo Uma obra de arte é depositária de um enorme número de desenhos; uns indispensáveis para a definição e realização de sua forma, outros secundários, mas não menos importantes, sempre permaneceram ao largo daqueles definitivos em estado de espera. Ao longo do tempo, esse numero de desenhos pode ir se acumulando, essa a sua grande riqueza. Como alternativa de aproximação à essa fortuna podemos então seguir o conselho de João Cabral de Melo Neto no poema 'A Educação pela Pedra" e, para aprender do desenho, como da pedra, outra vez frequentá-lo.

Palavras-chave: desenho, projeto de arquitetura, educação.

\section{To learn from the stone: to go to it often}

\begin{abstract}
A work of art is a depository of a huge number of drawings; some indispensable for the definition and realization of its form, other secondary, but no less important, always remained off the definitive ones in a state of waiting. Over time, this number of drawings can accumulate, and this is their great wealth. As an alternative to this fortune, we can then follow the advice of João Cabral de Melo Neto in the poem 'A Educação pela Pedra' and, to learn from drawing, as from stone, again attending it.
\end{abstract}

Key words: drawing, architectural design, education.

\section{Para aprender de la piedra, frecuentarla}

Resumen Una obra de arte es depositaria de un enorme número de dibujos; unos indispensables para la definición y realización de su forma, otros secundarios, pero no menos importantes, siempre permanecieron frente a aquellos definitivos en estado de espera. A lo largo del tiempo, ese número de dibujos puede ir acumulándose, y esa es su gran riqueza. Como alternativa de aproximación a esa fortuna podemos entonces seguir el consejo de João Cabral de Melo Neto en el poema 'La Educación por la Piedra' y, para aprender del dibujo, como de la piedra, otra vez frecuentarlo.

Palavras clave: diseño, diseño de arquitectura, educación. 


\section{Sombra e rapidez}

Partindo de duas imagens, duas referencias gerais diferentes, colocaremos a ideia do desenho em uma perspectiva histórica e possível no âmbito da formação em arquitetura. Essas imagens guiam o texto de forma indireta e conduzem nossa reflexão. A primeira imagem é uma interpretação sobre o mito da origem do desenho, contado por Plinio il Vecchio em sua "Storia Naturale" e a interpretação foi elaborada pelo arquiteto e professor Daniele Vitale.

O mito nos conta que no inicio da civilização o desenho teria nascido assim: uma jovem e seu amado estão deitados in um lugar solitário sob o sol. O amado dorme e a jovem o contempla plena de amor. Vê a sua sombra projetada na rocha e traça o contorno da sombra com uma pedra escura.

A interpretação é essa:

"Este mito diz coisas profunda e singulares. A primeira é que o desenho nunca reproduz a coisa, reproduz a sua sombra. A sombra não é a coisa, mas seu simulacro, uma espécie de projeção da coisa."

"A sombra suporta e sofre uma própria e obscura condenação, deve seguir sempre a coisa à qual é atada. Mas esse vinculo comtempla ao mesmo tempo a perda da consistência, da materialidade da coisa."

"A primeira característica da sombra é de mudar continuamente, com o angulo do sol, com as horas do dia e com s movimentos do corpo. A segunda é de poder desaparecer e aparecer ao improviso, com o passar do tempo, com o sol, com uma nuvem, ou ainda quando escurece. A terceira característica é de ser implacável em sua exatidão. A sombra não tem exceção possível, porque é governada por uma lei sem desvio, que é a lei da luz. Portanto a sombra é um esquema, é uma essência imaterial e é uma ideia fragilíssima. "(VITALE 2013)

A segunda imagem é retirada de um dos capítulos do livro Seis propostas para o próximo milênio de Italo Calvino. Nesse livro, recolha das conferencias preparadas para a Universidade de Harvard, a lição sobre a rapidez é concluída por Calvino recontando essa estória chinesa que transcrevemos aqui:

Entre as muitas virtudes de Chuang-Tzu existia a habilidade com o desenho. O rei pediu a ele o desenho de um caranguejo. Chuang-Tzu disse que precisava de cinco anos de tempo e de uma vila com doze servidores. Depois de cinco anos o desenho

*Joubert José Lancha é arquiteto, professor associado do Instituto de Arquitetura e Urbanismo da Universidade de São Paulo. ainda não havia sido começado. Necessito de outros cinco anos, disse Chuang-Tzu. O rei concordou com ele. Ao final dos dez anos, Chuang-Tzu pegou um pincel e num instante, com um único gesto, desenhou um caranguejo, o mais perfeito caranguejo como talvez nunca tenha sido visto. (CALVINO 1988) 
1 Sartre, Jean-Paul. Alberto Giacometti. Ed. Martis Fontes, SP, 2012, p.67.

\section{Duplo caráter}

Diversos autores discutem sobre a ambiguidade do desenho, sobretudo quando este é ainda em um estado inicial e tem o escopo de um croquis, serve a dar partida na elaboração de uma forma. Essas latentes ambiguidades de um desenho inicial e impreciso que representa, ao mesmo tempo, o objeto imaginado e o sujeito que o imagina, refletem a recusa voluntaria do desenho em "ser mais preciso que a percepção"1.

Esse duplo caráter do desenho forjado ao longo do tempo, de refletir a construção do sujeito e do objeto deve ser amplamente valorizado e estimulado na formação daqueles que lidam com a constituição da forma. Esse desenho ambíguo, limiar entre a imaginação e concretude da forma, transita entre um anseio impalpável e uma realidade tangível, e adensado de linhas possíveis amplia ainda mais seu valor no campo da página e no arco do tempo.

Para além da solução contingencial, aquilo que desse desenho pode emergir e devemos ser conscientes disso, são as grandes possibilidades abertas por essa indeterminação inerente à esses registros. Esses podem materializar ideias e conceitos, tornando-se cada vez mais claro a quem os propõe, e ao mesmo tempo tornar relevante também uma instabilidade que gera desconfiança nas soluções que se apresentam e portanto abrem e ampliam possibilidades de pesquisa de outras formas e alternativas para o mesmo ou para um novo problema.

Os desenhos iniciais, mas não só eles, constituídos por linhas de aproximação, podem ser assim, observados por aquilo que não é de fato sua fatura, pelos vazios entre as linhas e por todas aquelas tantas que estão vizinhas. A identificação desse desenho ambíguo, onde observamos alternativas diversas, mostra que ele tem estreitas ligações com os processos de projeto desenvolvidos ao longo da história da arquitetura, onde a relação entre o edifício e seu desenho se modificou continuamente. Para o ensino e para a investigação da arquitetura esta é uma questão aberta, sempre viva e inquietante.

Desenhar não é só adquirir conhecimento e praticar um oficio, mas é sobretudo pesquisar e experimentar alternativas. No ensino da arquitetura o desenho é de grande utilidade para procurar a essência e a natureza do espaço que se quer projetar ou que se está diante. Através de um processo analítico, de observação de casos particulares é possível estudar as relações compositivas, proporcionais, as escalas, os volumes, a estrutura, as relações com o contexto e outros tantos fatores imateriais como a luz, a sombra ou a cor.

O olhar, é o instrumento inicial. Não é um olhar qualquer, mas um olhar atento, curioso, um olhar que procura as contradições no objeto. A percepção se torna um modo de aprender e o desenho se apresenta como um instrumento para compreender melhor o mundo e dar a ele um significado pessoal. Através da capacidade de observação, através da analise, da seleção, da compreensão, a memoria, o juízo, o desenho cria uma consciência perceptiva. O desenho a mão tem um valor não substituível, não só pelas características pessoais, mas sobretudo porque leva a percepção ao nível da consciência.

Nas relações entre a obra e o desenho, ou entre a cidade e o desenho, é necessário partir da compreensão do fato que, o edifício fecha dentro de si próprio um mundo 
mais amplo. Os desenhos, suas sombras, abrem alternativas e permitem a leitura da obra a partir de vários pontos de vista. O desenho se torna um terreno de conflito, onde se realiza uma luta e se abre uma oportunidade de ir além. Por isso o desenho impulsivo e rápido deve ser recuperado e deve tornar a ser parte da didática da arquitetura. O croquis alimenta e estabelece um confronto entre o pensamento sobre o espaço e a distribuição espacial das ideias. E o faz sobretudo pelas suas características de abstração e por suas imprecisões e ambiguidades. É necessário portanto conferir novamente valor às qualidades intrínsecas do desenho à mão, nos processos de elaboração do projeto, seja no campo da arquitetura, seja no campo do design. Depois de uma certa euforia pelo uso dos programas de desenho digital, o debate começa a tornar mais claro as funções de cada tipo e se torna evidente a importância do retorno ao desenho livre nas primeiras fases de desenvolvimento do projeto. É importante porém observar o advento das tecnologias para a captura digital do movimento, representado pelo crescente investimento no campo das interfaces intuitivas e cinestésicas. Esses periféricos não repetem as características dos meios tradicionais e o processo do desenho ganha uma nova semântica através do uso desses instrumentos, onde as várias logicas e modos de pensar se misturam e se influenciam. Um verdadeiro processo de ressignificação dos meios até hoje disponíveis. O desenho à mão mantem suas características fundamentais, como a imprecisão ou como a vizinhança ao pensamento do projetista, e sem contradições com as possibilidades cognitivas próprias dos meios digitais.

Considerando o ato do desenho como uma educação do olhar, entendemos colocar em discussão se esse olhar, pode também em um ambiente digital, continuar a desenvolver o seu papel, abrindo outras dimensões e possibilidades processuais.

\section{Desenho: campos teórico e prático}

A atividade de projeto pode ser entendida como um conjunto de ações e procedimentos utilizados para descrever um objeto, que é inexistente ao início do processo. É um percurso que se desenvolve por aproximações sucessivas. Os procedimentos são diversos mas os percursos podem ter o seu inicio no desenho livre (os croquis de estudos preliminares). As formas vão se precisando através dos desenhos sempre mais acurados (desenhos técnicos), nos quais o sistema gráfico, é normatizado e as formas são perfeitamente definidas.

Um primeiro aspecto dos croquis é que é feito à mão e ao mesmo tempo é veloz. O croquis consente que a mão siga a imprevisibilidade e a descontinuidade do pensamento. Consente reconduzir a trama das formas para uma substancia mais profunda e mais longínqua. É possível exprimir diversas logicas de pensamento através do desenho. 0 gesto rápido permite, com uma singular ação, instaurar relações lineares com a coisa desenhada e permite a sua percepção em modo integrado e generalizado.

O desenho, para além de sua função documental, é um importante instrumento de interpretações, analises e compreensões de obras ou elementos, espaços e lugares. A representação gráfica vai além do simples registro mecânico, é o resultado de sentimentos, percepções e olhares críticos. $O$ desenho pode consentir uma compreensão mais dilatada e reflexiva do território, da paisagem, da cidade e da arquitetura. 
2 Aldo Rossi. Autobiografia scientifica. II Saggiatore, Milano ed.2009, p.45
O desenho é um meio de expressão que pertence à cultura, à sociedade, à cidade. Mas antes do gesto do desenho existe a percepção do objeto, os indivíduos e seus vínculos. Aldo Rossi em uma entrevista de 19... diz: "La mia più importante educazione formale è stata l'osservazione delle cose; poi l'osservazione si è tramutata in una memoria di queste cose. Ora mi sembra di vederle, tutte disposte come utensili, in bella fila; allineate come in un erbario, in un elenco, in un dizionario".2

Para Bosi (in NOVAES 1998) o olho é um limite móvel e aberto entre o mundo externo e o sujeito. Recebe estímulos luminosos e se move à procura de alguma coisa, que o sujeito deve distinguir e conhecer. Existe um ver-para-ver sem o ato intencional de olhar e existe um ver como resultado de um olhar ativo.

O arquiteto vê o ambiente construído, vê na arquitetura e na cidade. Mas o que significa perceber o espaço? A percepção é uma representação fiel à realidade? Nela, representação e sujeito interagem com o objeto, modificando-o. A percepção é condicionada das condições do lugar e do tempo. Todavia, segundo Merleau-Ponty , o processo de percepção do mundo se realiza através daquilo que os psicólogos chamam experiência do erro; nós "construímos a percepção com o percebido". Substituímos a experiência direta utilizando os registros de experiências precedentes. É difícil distinguir e compreender as experiências novas daquelas já superadas. (MERLEAUPONTY 1994, pag. 25).

É oportuno aqui, resgatar uma definição que, ao longo do séculos foi sempre reproposta quando se afronta o tema da escultura, esta comparece no tratado De Statua, escrito provavelmente nos primeiros anos da segunda metade do século XV e publicado pela primeira vez em tradução italiana datada de 1568 por Cosimo Bartoli, realizada a partir do original latino. Leon Battista Alberti logo no primeiro parágrafo de seu testo, discorre sobre a hipótese de quais teriam sido as primeiras motivações para a realização em arte, escreve que os homens, procurando criar imagens e semelhanças com elementos da natureza, observando "com muito cuidado", elementos como por exemplo, o tronco de uma arvore ou uma massa de terra, começaram a raciocinar se poderiam deles, acrescentar ou retirar alguma coisa, para "colher e exprimir completamente o verdadeiro aspecto de uma imagem. Assim, corrigindo e refinando algumas de suas linhas e superfícies, seguindo as sugestões advindas da própria coisa, conseguiram o seu propósito e certamente com prazer. ".

Esse processo portanto, que parte do olhar se desenvolve através da percepção e da criação, chega à representação. Para Dworecki existe a representação quando o percebido, a consciência de perceber, as intenções e as técnicas aderem à expressão. É como imprimir um traço da personalidade, que se torna desenho. A expressão se torna uma representação através de um ato de redução. Para o autor seja a "expressão" que a "representação" são fatos de cultura. (DWORECKI 1998)

Do ponto de vista cultural e individual, o desenho tem um grande e decisivo papel na criação e no desenvolvimento das ideias em arquitetura. Pensar, olhar e desenhar, nas suas diversas interações é a matriz da qual deriva a concepção do projeto. Nesse sentido o desenho como meio de representação não é nunca indiferente, passivo e objetivo; é parte ativa das intenções do arquiteto. No diálogo entre o arquiteto e seu projeto, a comunicação se realiza através do desenho. Uma relação que Gregotti 
define como: "I'unico rapporto corporeo rimanicene che l'architetto compie con la fisicità della materia che dovrebbe costituire: è la sua ultima "manualità" e lui deve difendere ostinatamente." (GREGOTTTI 2010, p. 25)

Todavia, segundo Duff (2005, in VASCONCELOS, 2006), não é possível pensar hoje o desenho, da mesma maneira de trinta anos atrás, porque existe uma nova gramatica e uma nova sintaxe criadas pelas novas tecnologias. A atividade do desenho muda e reflete o contexto do seu tempo. Mas devemos notar que o momento atual é ligado à convivência entre as diversas modalidades de representação.

Certo é que existem mudanças operativas no mundo ao qual a representação digital opera. O processo de projetação se fraciona. Na projetação assistida pelo computador, os produtos se tornam neutros e livres de qualquer caráter pessoal ou interpretativo. Diferente do desenho tradicional, que permite a interação imediata entre autor e projeto, os programas digitais, como sugere o termo, necessitam de uma série de operações em sequencia para a execução do desenho. Uma técnica não substitui a outra, mas acrescenta novas oportunidades para trabalhar em modo integrado. Não é uma questão, o progresso atribuído ao CAD porque facilita e reduz o tempo de execução de um desenho, além de fornecer e garantir uma acurada técnica que o desenho a mão não consegue se equiparar.

Atualmente o Building Information Modeling (BIM) é um dos instrumentos mais prometente no campo da arquitetura, da engenharia e da construção. Graças ao advento da parametrização e das inovações digitais, se experimenta um reexame das teorias e dos métodos projetivos. Mas aquilo que é importante colocar em evidencia, não é a substituição de um processo por outro, mas a abertura para novas possibilidades para a projetação. Segundo Righi (2008) os estudos indicam que o processo de parametrização das soluções com o sistema CAD, requer uma simplificação da proposta originária. Se perde a imprecisão dos croquis e dos estudos preliminares que dão flexibilidade às ações dos arquitetos. (RIGHI 2008)

Com essa explosão operativa dada pelo uso do computador, e com a pesquisa de uma perfeição operativa através da realidade virtual ocorre uma grande tensão no desenho. Para Uria, vivemos uma crise do desenho, e nos novos tempos a imagem regrediu como registro comunicativo e narrativo. A tecnologia da simulação virtual dobra a realidade sem alguma transformação. Discutimos se esta nova linguagem experimental e especulativa da infografia, que procura ou tenta representar tudo aquilo que é "pensável", não transforme os artistas em editores gráficos, em operadores e em espertos das imagens

Nesse sentido, enquanto o software permite infinitas combinações (ou quase), existe um outro tema para ser discutido, o campo cognitivo do desenho projetivo. O desenho mediado pelo display digital consente de desfrutar a novas características técnicas e de combina-las com a imprevisibilidade e a fruição do desenho a mão. A ligação entre o corpo, a mente e a expressão se realiza ainda no processo analógico do desenho feito à mão.

Os dispositivos para a captura dos movimentos aplicados na produção dos dados gráficos, são instrumentos propícios para estabelecer uma ponte entre o desenho 
analógico e digital. É possível capturar a pressão e a velocidade do gesto realizado sobre a tela com uma caneta digital, aproximando assim o processo de emissão dos dados no computador à imprecisão e ambiguidade do gesto próprio do desenho à mão. É importante notar que esta não é uma simples mudança de suporte, do papel para a interface digital, mas a abertura que possibilita uma sinergia entre as duas logicas e as duas grafias. O processo de sistematização que é próprio do software, pode, combinado com o imediatismo do desenho a mão; estabelecer um processo de recomposição consentido pelos novos aparelhos digitais.

A discussão sobre o papel da exercitação gráfica na formação do arquiteto, é muito importante porque é correlata ao debate sobre a arquitetura, em um momento de transição no qual coexistem posições diferentes a proposito do desenho. De um lado um desenho preciso e detalhado que tem o seu papel nas relações sociais e produtivas; de outro lado um desenho que assume características espetaculares chegando ao ponto de cancelar a própria arquitetura; de um lado a retomada eufórica do desenho, de outro a sua eliminação pelos novos meios do mundo da infografia. (URIA, 2007, p. 50)

\section{Frequentar o outro lado da linha}

Um edifício retém dentro de si, uma certa quantidade de desenhos que se assemelham a um tesouro escondido, e tão bem escondidos que muitas vezes para compreender sua lógica nossa única escolha é de propor ou oferecer um outro desenho que, como um texto pode recolocar em liberdade as ideias que permaneceram na sombra. Ideias que por serem sombras são ao mesmo tempo precisas e frágeis. Esse tesouro feito de certezas, mas também e sobretudo de duvidas pode consentir diversas possibilidades de pesquisa, comentário ou mesmo de abertura para novas proposições. Podemos então nos convidar a outra vez desenhar, levantando hipóteses possíveis de como aquele edifício, no seu processo de imaginação e confronto com as diversas condicionantes, poderia ter tomado uma ou outra forma, novamente imaginando alternativas para sua solução ou mesmo tomando-os como princípio de uma outra criação.

Os textos sobre a obra de arte e de arquitetura, realizados no tempo pelo autor ou por aqueles que a comentam ou a interpretam, e os desenhos iniciais, e aqueles realizados em seguida, podem trazer essa mesma tensão. Podemos imaginar que, como nos textos, no desenho, as linhas esquecidas, linhas vizinhas àquelas definitivas, funcionam como um segredo ou uma riqueza escondida. Os processos no decorrer do tempo tendem a acumular-se, e se tornam, como escreve Henri Focillon, uma espécie de "vegetação luxuriante", que gira entorno da forma. Nos processos esta presente uma parte de um trabalho original, e isso é um aspecto da "vida imortal" da forma. (FOCILLON 1990, p.23).

\section{Referências bibliográficas}

\section{Monografias}

CALVINO 1990: CALVINO, Italo. Seis propostas para o próximo milênio. Companhia das Letras São Paulo, 1990.

DWORECKI 1998: DWORECKI, Silvio. Em busca do traço perdido. São Paulo: Scipione - Editora da Universidade de São Paulo, 1998. 
FOCILLON 1990: FOCILLON, Henri. Vita delle Forme. Turim: Einaudi, 1990.

MERLEAU-PONTY 1994: MERLEAU-PONTY, Maurice. Fenomenologia da percepção. São Paulo: Martins Fontes, 1994.

NOVAES 1988: NOVAES, Adauto et al. O olhar. São Paulo: Companhia das Letras, 1998.

SCHENK, Leandro Rodolfo. Os croquis na concepção arquitetônica. São Paulo: Annablume, 2010.

VITALE 2013: VITALE Daniele. I/ disegno. "Come la testa recisa di Orfeo» in Festschrift L'opera sovrana Studi sull'architettura del XX secolo dedicati a Bruno Reichlin. Mendrisio. Academy Press / SilvanaEdito'riale 2013.

\section{Artigos em revista}

URIA 2007: URIA, Leopoldo. Expansión y crisis del dibujo: reflexiones sin imágenes. In Revista EGA - expresión gráfica arquitectónica, Valência,año 12, 2007.

\section{Ensaios em atos de Seminários}

RIGHI 2008: RIGHI, T. A .F; Celani, G. Esboços na era digital: uma discussão sobre as mudanças na metodologia de projeto arquitetônico. Congresso Iberoamericano de gráfica digital SIGRADI. In Anais... Havana Cuba 2008.

VASCONCELOS 2006: VASCONCELOS, 2006: MARIA VASCONCELOS, Helena Elias. Questioning drawing for designers: Project work as a strategy and examples from practice. In 2006 Desining Research Society. International Conference in Lisbon. IADE. 